\title{
The mapping of cortical activation by near-infrared spectroscopy might be a biomarker related to the severity of fibromyalgia's symptoms
}

\section{Daniela Gabiatti Donadel}

Federal University of Rio Grande do Sul

Maxciel Zortea

Federal University of Rio Grande do Sul

Iraci Lucena da Silva Torres

Hospital de Clínicas de Porto Alegre

Felipe Fregni

5Berenson-Allen Center for Noninvasive Brain Stimulation; Beth Israel Deaconess Medical Center; Physical Medicine \& Rehabilitation, Department of Neurology, Harvard Medical School, Boston, USA

Wolnei Caumo ( $\nabla$ wcaumo@hcpa.edu.br)

Federal University of Rio Grande do Sul

\section{Research Article}

Keywords: near-infrared spectroscopy, prefrontal cortex, motor cortex

Posted Date: February 25th, 2021

DOl: https://doi.org/10.21203/rs.3.rs-240389/v1

License: (c) (1) This work is licensed under a Creative Commons Attribution 4.0 International License. Read Full License

Version of Record: A version of this preprint was published at Scientific Reports on August 3rd, 2021. See the published version at https://doi.org/10.1038/s41598-021-94456-2. 


\section{The mapping of cortical activation by near-infrared spectroscopy might be a biomarker related to the severity of fibromyalgia's symptoms}

Daniela Gabiatti Donadel ${ }^{1,2}$, Maxciel Zortea ${ }^{1,2}$, Iraci Lucena da Silva Torres, ${ }^{3}$ Felipe Fregni, ${ }^{4}$ Wolnei Caumo ${ }^{1,2,5,6}$

${ }^{1}$ Post-graduation Program in Medical Sciences, School of Medicine, Universidade Federal do Rio Grande do Sul (UFRGS), Porto Alegre, Brazil

${ }^{2}$ Laboratory of Pain and Neuromodulation at Hospital de Clínicas de Porto Alegre (HCPA), Porto Alegre, Brazil

${ }^{3}$ Pharmacology of Pain and Neuromodulation: Pre-clinical Investigations Research Group at Hospital de Clínicas de Porto Alegre (HCPA), Porto Alegre, Brazil

${ }^{4}$ Berenson-Allen Center for Noninvasive Brain Stimulation; Beth Israel Deaconess Medical Center; Physical Medicine \& Rehabilitation, Department of Neurology, Harvard Medical School, Boston, USA

${ }^{5}$ Pain and Palliative Care Service, Hospital de Clínicas de Porto Alegre (HCPA), Porto Alegre, Brazil

${ }^{6}$ Pain and Anesthesia in Surgery Department, School of Medicine, Universidade Federal do Rio Grande do Sul (UFRGS), Porto Alegre, Brazil

CORRESPONDING AUTHOR: Wolnei Caumo MD, PhD; Department: Laboratory of Pain and Neuromodulation; Institution: Hospital de Clínicas de Porto Alegre at UFRGS. Address: Ramiro Barcelos, 2350 - CEP 90035-003 Bairro Rio Branco - Porto Alegre - RS. Phone: (55) 51- 3359.8083. Fax: (55) 51- 3359.8083

\section{EMAIL ADDRESSES OF CO-AUTHORS:}

Daniela Gabiatti Donadel (dgdonadel@gmail.com)

Maxciel Zortea (max.zortea@gmail.com)

Iraci Lucena da Silva Torres (iltorres@ @cpa.edu.br)

Felipe Fregni (Fregni.Felipe@mgh.harvard.edu)

Wolnei Caumo (wcaumo@hcpa.edu.br) 


\begin{abstract}
We compared the activation pattern at the motor cortex (MC and prefrontal cortex (PFC) based on the delta value $(\Delta)$ of oxy-hemoglobin $(\mathrm{HbO})$ by functional near-infrared spectroscopy (fNIRS). We examined the relationship of the $\Delta \mathrm{HbO}$ based on the peaks at $5^{\circ} \mathrm{C}$ and $25^{\circ} \mathrm{C}$ by right-hand immersion in water in 22 fibromyalgia and 19 controls. Fibromyalgia showed a shorter peak latency for $\mathrm{HbO}$ at the left MC. In contrast, at the left MC, their $\mathrm{HbO}$ increased $117.64 \%$ compared to $92.85 \%$ in the controls. A receiver operator characteristics (ROC) analysis showed the $\Delta \mathrm{HbO}$ cutoffs equal to -0.175 at the left and 0.205 at the right PFC offer sensitivity and specificity of at least $80 \%$ in screening fibromyalgia compared to controls. In fibromyalgia, a ROC analysis showed that these cutoff points could discriminate those with higher disability due to pain and more severe central sensitization symptoms (CSS). The ROC with the best discriminatory profile was to the CSS score with the $\triangle \mathrm{HbO}$ at the left PFC (AUC $=0.82$, CI $95 \%=0.61-100)$. These results indicate that cortical activation based on the $\Delta \mathrm{HbO}$ at the PFC might be a sensitive marker to identify those fibromyalgia patients with more severe clinical symptoms.
\end{abstract}




\section{INTRODUCTION}

Fibromyalgia is a widespread chronic pain disorder accompanied by numerous other symptoms that cause significant functional impairment, a prototypical condition of central sensitivity syndrome (CSS). ${ }^{(1,2)}$ Also are typical symptoms of fibromyalgia: sleep disturbance, joint stiffness, headache, abdominal discomfort, cognitive impairment, and depressive symptoms. ${ }^{(1)}$ According to an early study with fibromyalgia, a higher score in the Central Sensitization Inventory (CSI) was positively correlated with serum brain-derived neurotrophic factor (BDNF) and dysfunction of the descending pain inhibitory system. ${ }^{(2)}$

Previous studies using functional magnetic resonance imaging (fMRI) in a resting state found different activation of brain areas involved in pain processing in patients with diverse types of chronic pain (e.g., neuropathic pain, fibromyalgia, etc.) compared to healthy subjects. ${ }^{(3,4)}$ In patients with orofacial neuropathic pain, increased functional connectivity within the brainstem pain-modulation network was found. This finding was observed in the rostral ventromedial medulla (RVM), ventrolateral periaqueductal gray (vlPAG), and locus ceruleus (LC). ${ }^{(3)}$ Another study with fibromyalgia found a positive correlation between changes in the primary somatosensory (S1) cortex's connectivity and clinical pain, catastrophizing pain, and autonomic dysfunction. ${ }^{(4)}$ Similarly, in healthy subjects, morphine attenuated the pain signal measured by functional near-infrared spectroscopy (fNIRS) in the medial Brodmann Area 10 and S1. ${ }^{(5)}$ In comparison, fibromyalgia showed an increase in oxyhemoglobin $(\mathrm{HbO})$ at the dorsolateral prefrontal cortex (PFC) upon painful stimulation compared to healthy controls. ${ }^{(6)}$

Studies conducted in healthy subjects offer insight into the underlying physiological principles and the transient dynamics of the vascular response by blood oxygenation leveldependent (BOLD) signals related to the local paramagnetic deoxy-hemoglobin (reduced hemoglobin, $\mathrm{HbR}$ ). Such studies found correlations between pain stimulus intensity and the 
magnitude of activation of cortical areas involved in pain processing. These areas include contralateral SI and bilateral second (SII) somatosensory cortice, ${ }^{(7)}$ as well as the PFC. ${ }^{(8)}$ However, to date, a limited number of studies have focused on the cortical activation speed at specific areas of emotion and pain processing, nominally the $\mathrm{PFC}^{(9)}$ and primary motor cortex (M1). ${ }^{(9,10,11)}$ These areas have received attention as targets for non-invasive brainstimulation (e.g., transcranial magnetic stimulation (TMS), transcranial direct current stimulation (tDCS), etc.). However, we need to comprehend better their relationship with pain processing in real time. With this perspective, fNIRS is a tool that provides detailed biochemical specificity in the form of $\mathrm{HbO}$ concentration changes within a microvascular space with high temporal resolution. ${ }^{(12,13)}$ fNIRS measures indicate the activation of cortical areas that are defined according to the experimental paradigm.

Thus, we compared activation patterns based on the delta value $(\Delta)$ of $\mathrm{HbO}$ in target areas involved in pain processing, nominally the PFC and motor cortex (MC), in fibromyalgia and healthy controls. In fibromyalgia, we examined the discriminatory properties of the $\triangle \mathrm{HbO}$ based on the peaks at $5{ }^{\circ} \mathrm{C}$ and $25^{\circ} \mathrm{C}$ at the PFC to identify subjects with more severe clinical symptoms. We hypothesized that fibromyalgia, as compared to controls, would present a showed a shorter peak latency and larger amplitude of $\mathrm{HbO}$ curves measured by fNIRS during two contrasting thermal stimuli (water at $25{ }^{\circ} \mathrm{C}$ and $5{ }^{\circ} \mathrm{C}$ ) at the PFC and MC.

\section{PATIENTS AND METHODS}

\subsection{Design Overview, Settings and Participants}


The protocol of this cross-sectional study was approved by the Committee Board (Institutional Review Board [IRB] at Hospital de Clínicas de Porto Alegre Ethics number 20170049), according to the Declaration of Helsinki. All participants provided written informed consent.

\subsection{Recruitment, Inclusion and Exclusion Criteria}

We included right-handed literate women aged between 18 and 65 years recruited from the Chronic Pain Clinic and Basic Health Unit of the Hospital de Clínicas de Porto Alegre, and referrals from other clinic units. Also, advertisement postings in public places in Porto Alegre and on the internet where used. Thereafter, volunteers were contacted by phone and screened for eligibility. For the FM group, participants had to have confirmed the diagnosis of FM according to the American College of Rheumatology. ${ }^{(1)}$ A skilled physician with experience in pain clinic re-examined patients and confirmed diagnosis. We excluded pregnant patients or women with a history of malignancy or uncompensated chronic diseases. For the control group (HC) were excluded participants who reported pain or frequent use of painkillers, pregnant, with clinical disease (e.g., diabetes, hypertension, etc.). Also were excluded if they have a history of neuropsychiatric comorbidities, use of benzodiazepines, anticonvulsant, or antidepressant drugs. Both groups were oriented to refrain from consuming stimulating drinks and alcohol at least six hours before the assessments.

\subsection{Outcomes}

The outcomes related to cortical activation were the peak latency of the $\mathrm{HbO}$, and the delta value of oxyhemoglobin $(\Delta \mathrm{HbO})$. The delta-values were obtained by the difference from baseline to the amplitude peak of the curves of $\mathrm{HbO}$ assessed bilaterally on the PFC and $\mathrm{MC}$ upon the thermal stimulus of $25^{\circ} \mathrm{C}$ and $5^{\circ}$. The delta value of oxyhemoglobin $(\Delta \mathrm{HbO})$ based on the peaks of $\mathrm{HbO}$ at $5 \mathrm{OC}$ and $25 \mathrm{OC}$ was a measure of maximum response upon each one of these two-thermal stimuli. The disability due to pain and central sensitization 
symptoms were the primary clinical outcomes in the fibromyalgia group. For the analysis that related to the clinical outcomes, the study's primary interest factor was the PFC activation assessed by the delta value of $\Delta \mathrm{HbO}$ - based on the peaks of $\mathrm{HbO}$ at $5^{\mathrm{O}} \mathrm{C}$ and $25^{\circ} \mathrm{C}$.

\subsection{Instruments and Assessments}

\subsubsection{Data Acquisition}

Cortical activation was evaluated by functional near-infrared spectroscopy (fNIRS), with a NirX NirScout 16x24 near-infrared spectroscopy device, scan rate 3,91 Hz, dualwavelengths LEDs sources (760 and $850 \mathrm{~nm}$ ) with 16 sources and 16 detectors spaced of 3 $\mathrm{cm}$ and placed over the scalp using the caps provided by EASYCAP®. The montage creates 40 channels and covers bilateral prefrontal and cortical motor areas. Probe localization was established using the international 10-10 EEG system (Table 1). Software equipment was NirsStar 14.2, NirsLab 2017, and MatLab (MATLAB 2010). In appendix I you can see the Relationship of fNIRS channels 1-20 and EEG 10-10 System to compose the channels used.

\subsubsection{Screening and Preprocessing}

The raw data from each subject was individually inspected with NirsLab, and all channels with coefficient variation $(\mathrm{CV})$ more than $7.5 \%$ were removed. Data were bandpassed from 0.01 to $0.2 \mathrm{~Hz}$. Considering an inter-optode distance of $3 \mathrm{~cm}$ and a differential path-length (DFP) of 7.25 and 6.38, the data was finally converted to $\mathrm{HbO}$ using the modified

Beer-Lambert law and exported to MatLab. Based on previous studies, ${ }^{(15)}$ we calculated the mean for $\mathrm{HbO}$ concentration at the 30 seconds baseline and defined three main measures: a) the latency (time in seconds) to reach the highest $\mathrm{HbO}$ concentrations after stimulus onset (peak latency); b) the range ( $\mathrm{HbO}$ peak amplitude) of $\mathrm{HbO}$ concentrations $(\Delta \mathrm{HbO})$ between 
baseline and during the first 15 seconds after thermal stimulus onset; and c) the range of $\mathrm{HbO}$ concentrations between baseline and the first 15 seconds after thermal stimulation ending (HbO_PSE). Therefore, peak latency and peak amplitudes after stimulus end were based on only $\mathrm{HbO} .^{(16)}$ We grouped channels in four cortical areas, based on EEG 10/10 system parameters and Broadmann's area (Figure 1): left and right PFC and left and right MC.

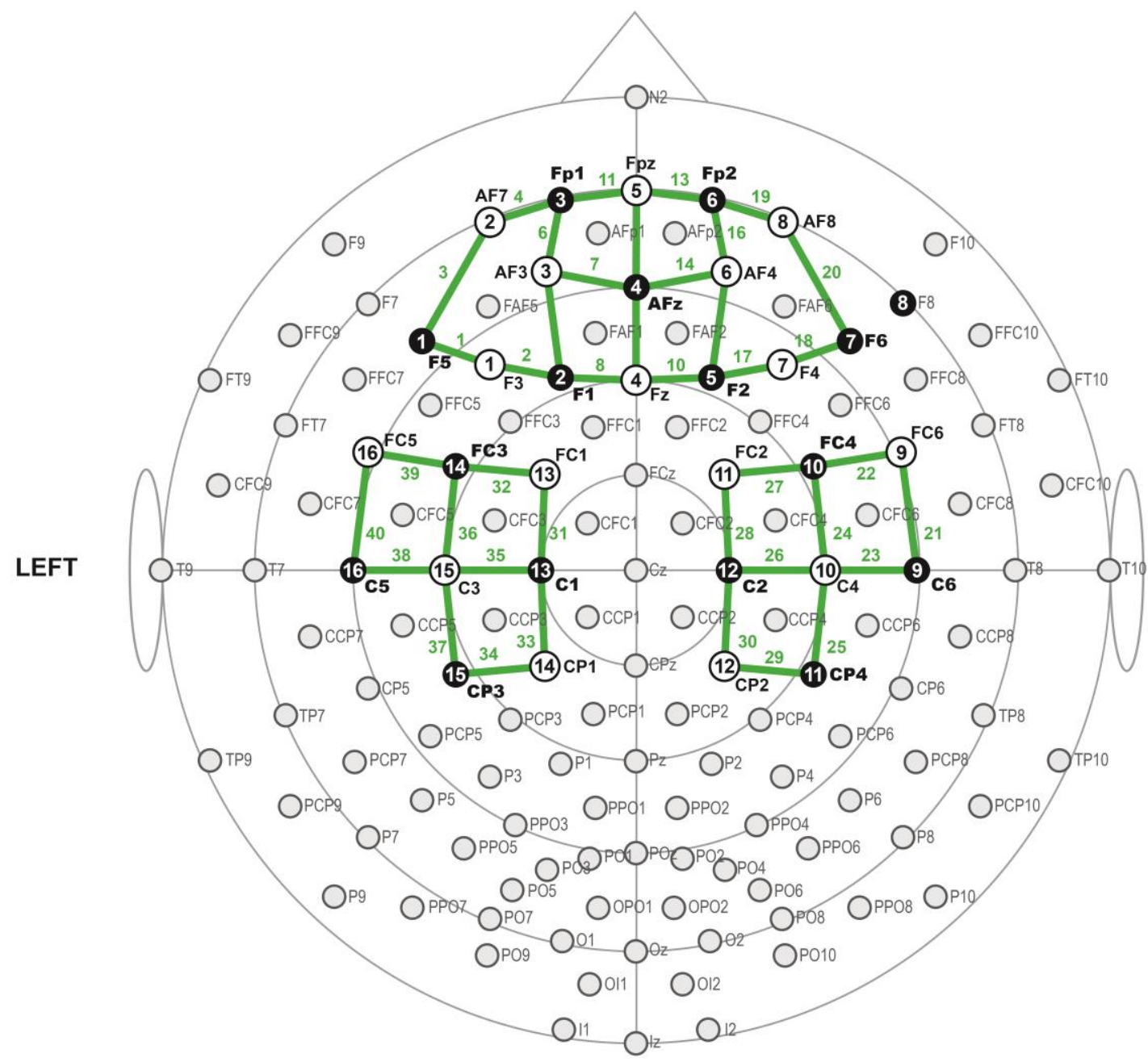

Figure 1. The fNIRS' optodes montage. Black dots represent detectors, and white dots represent sources. LEFT PREFRONTAL CORTEX = Channel 1-9 plus 11 and 12. RIGHT 
PREFRONTAL CORTEX-Channel 12 - 20 plus Channel 9 and 10. RIGHT MOTOR CORTEX - Channel 21-30. LEFT MOTOR CORTEX - Channel 31-40.

\subsubsection{Experimental Paradigm}

Subjects were sitting in a comfortable chair with their arm rested, lights turned off, and room temperature kept constant (around $21^{\circ} \mathrm{C}$ ) during the experiment to minimize contamination. After explaining, demonstrating, and solving doubts about each thermal stimulation, subjects were asked to remain with their eyes closed and to reduce any kind of motor activity not related to the experiment. After verifying the correct positioning and adequate signal capture, we proceeded to data registering. The signal was recorded for 60 seconds in a resting state, as the baseline measure. Thermal stimulation was performed while recording the cortical activation for posterior offline analysis. Thermal stimulation consisted of participants immersing their hands on the water in a bucket with two different temperatures: $25^{\circ} \mathrm{C}$ (innocuous) and $5^{\circ} \mathrm{C}$ (noxious) for 30 seconds or until feeling the first pain sensation. The participant rested for 2 minutes after each test. The water temperature during the experiment was recorded by a digital thermometer. The total time of the experimental paradigm was around 15 to 20 minutes. Figure 2 illustrates the paradigm used. 


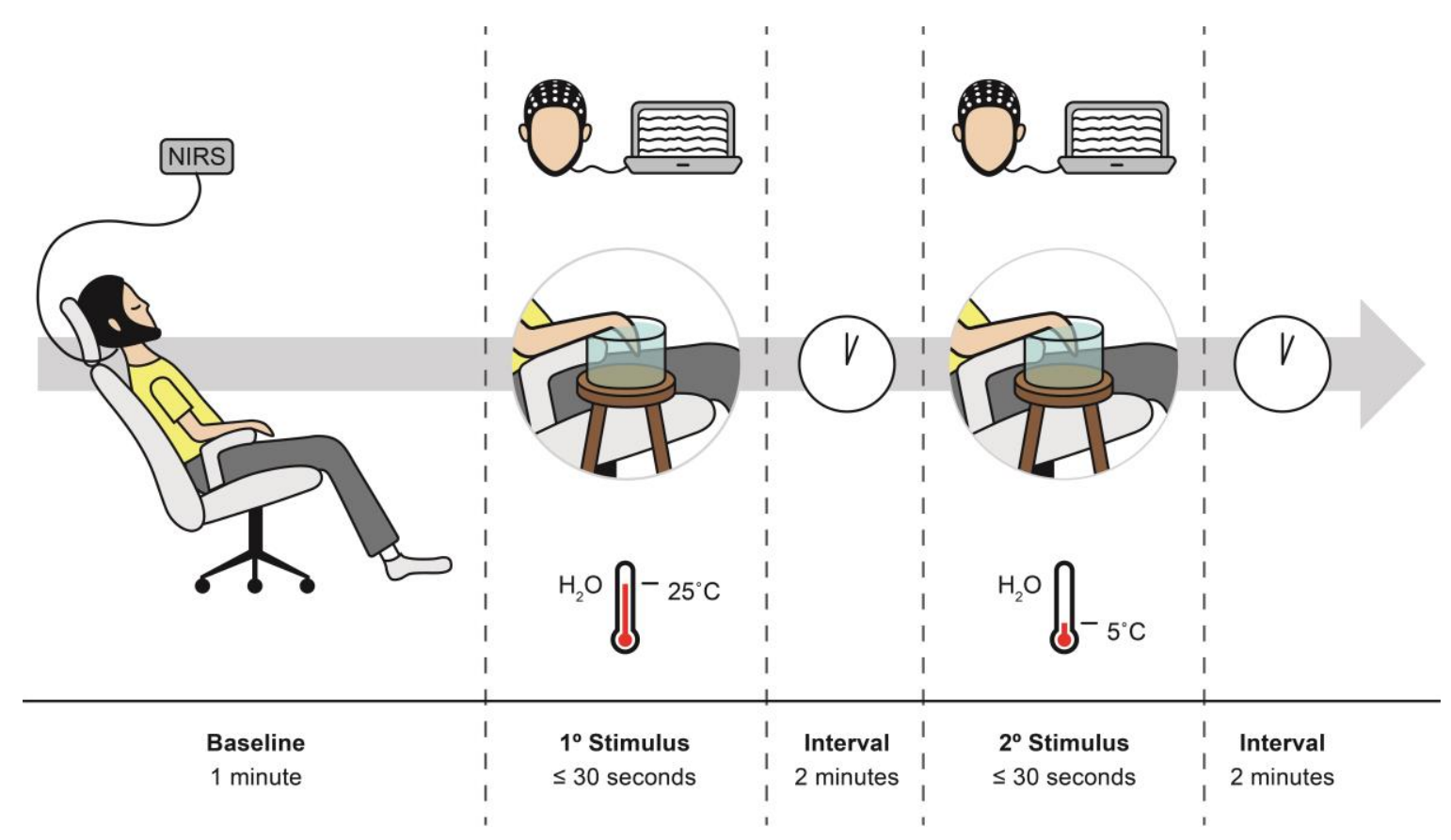

Figure 2. Timeline of the experimental paradigm. Timeline of each assessment pre- and post-thermal stimuli with the temperature at $25^{\circ} \mathrm{C}$ and $5^{\circ} \mathrm{C}$. The cold test was induced by the immersion of the right hand in the water for 30 seconds or until feeling the first pain sensation, with the temperature of $25^{\circ} \mathrm{C}$ and $5^{\circ} \mathrm{C}$ and a break of 2 minutes between each trial. The temperature was controlled through a digital thermometer.

\subsubsection{Assessment of pain disability due to pain and central sensitization symptoms}

a) The Brazilian Portuguese version of the Profile of Chronic Pain: Screen (BPCP: S) ${ }^{(17)}$ was used to assess the disability due to pain (DRP) for daily activities. It assessed the level of disability due to pain, and it consists of 15 items (total score from 0 to 91). The scale comprehends three parts: severity scale [two items in 6-points Likert scale and two in numeric scale (0-9 in intervals of 0.5 units), possible range $0-30]$, interference scale (six items in 6-points Likert scale; possible range 0-36), and emotional burden scale (five items in 5-points Likert scale; possible range 0-25).

b) The Central Sensitization Inventory for Brazilian Population (CSI-BP) consists of 25 items (total score from 0 to 100) loading for the factors: physical symptoms, emotional distress, 
headache/jaw symptoms, and urological symptoms. This scale allows a rapid tracking of symptoms associated with central sensitization to guide therapeutic strategies and indicate prognostic factors. Higher scores indicate a higher degree of self-reported symptomatology. Additionally, the part B of SCI assesses the presence of psychiatric diagnosis and neurological disorders associated with central sensitization. ${ }^{(18)}$

\subsubsection{Assessment of sociodemographic characteristics and other psychological measures}

We used the Beck Depression Inventory (BDI-II) ${ }^{(19)}$ for depressive symptoms, StraitTrait Anxiety Inventory - short version (STAI-SV) ${ }^{(20)}$ and Brazilian Pain catastrophizing Scale (BP-PCS) ${ }^{(21)}$ were applied for sample characterization purposes. Standardized questionnaire: a standardized query was used to assess demographic data and medical comorbidities. Patients were requested to provide information about their age, sex, level of education, marital status, and lifestyle habits. They also provided information about their health status, including clinical and psychiatric diagnoses. Analgesic use was defined by an average of analgesic used per week during the previous month. For data analysis, analgesic use was included as a dichotomous variable (the use of analgesics at least four or fewer days per week or the use for more than 4 days per week). This approach was chosen because patients with chronic pain rescue analgesic use change each week, depending on their level of pain.

\subsection{Data Analysis}

All continuous variables were tested for normality using the Shapiro-Wilk's test and Box-Plot diagrams. The majority presented an indication of non-parametric distributions. Therefore, for sample characterization, we used Mann-Whitney U tests for continuous variables and Fisher's Exact Tests for categorical variables. We conducted Generalized 
Estimating Equations (GEE) models with an exchangeable working correlation to compare for the group effect (fibromyalgia and controls) on the peak latency of the $\mathrm{HbO}$, and the delta value of oxyhemoglobin $(\Delta \mathrm{HbO})$. Also, we used the GEE to compare the delta-values from baseline to the amplitude peak of the curves of $\mathrm{HbO}$ on the left and right PFC and MC upon the thermal stimulus of $25^{\circ} \mathrm{C}$ and $5^{\circ} \mathrm{C}$. In the final models, interactions among the factors (group and temperature) were also examined. Effect sizes were reported according to Cramer's V [(for one degree of freedom the effect size is classified as small (0.1), medium (0.3) and large (0.5)]..$^{(22)}$

The Spearman's rho coefficient was used to assess the relationship between the left and right $\mathrm{PFC}$ activation assessed by the delta value of $\triangle \mathrm{HbO}$ - based on the peaks of $\mathrm{HbO}$ at $5^{\circ} \mathrm{C}$ and $25^{\circ} \mathrm{C}$ with the disability due to pain and central sensitization symptoms in fibromyalgia (see Table 4). After confirming the corresponding assumptions, a multivariate linear regression model was performed to adjust for multiple comparisons between the independent variables the delta value of $\Delta \mathrm{HbO}$ - based on the peaks of $\mathrm{HbO}$ at $5^{\circ} \mathrm{C}$ and $25^{\circ} \mathrm{C}$ on the right and left PFC to explore their relationship with clinical symptoms observed in FM (i.e., disability due to pain and central sensitization symptoms). The dependent variables were scores in the scores related to disability due to pain for daily activities (BP-PCP:S) and central sensitization scores (CSI-BP). All analyses were adjusted by multiple comparisons using the Bonferroni's Multiple Comparison Test. The AUCs with exact binomial 95\% confidence intervals (CI) are presented. The cutoff values with the highest Youden index, with $80 \%$ sensitivity and with $80 \%$ specificity is presented each one of four indexes and all they showed a ROC AUC higher than 0.68.

For the analysis regarding an association between the cortical activation related to the $(\Delta) \mathrm{HbO}$ based on the peaks of $\mathrm{HbO}$ at $5^{\circ} \mathrm{C}$ and $25^{\circ} \mathrm{C}$ on the PCF with fibromyalgia symptoms, a priory sample size estimative indicated a study of 20 subjects. For type I and II 
errors of 0.05 and 0.20 , respectively, and anticipating effect size of 0.6 for multiple regression analysis, which allows for two predictors [in the case, the $(\Delta) \mathrm{HbO}$ based on the peaks of $\mathrm{HbO}$ at $5^{\circ} \mathrm{C}$ and $25^{\circ} \mathrm{C}$ on the left and on the right $\mathrm{PCF}$. Finally, considering the likely attrition rate and other unexpected factors, we increased the sample by $10 \%$, and the required sample size was 22 patients. ${ }^{(23)}$ All analyses considered a significance level of $\alpha<$ 0.05 for two-tailed tests. To analyze the data, we used the software SPSS version 22.0 (SPSS, Chicago, IL, USA).

\section{RESULTS}

\subsection{Sample Characterization}

A total of 46 volunteers were enrolled in the study, and five were excluded (one from the FM group due to problems with the fNIRS registration and four from the HC group due to acute illness and use of antidepressant). The comparisons between groups related to sociodemographic and clinical characteristics are presented in Table 1. Groups differed significantly in all characteristics, in a sense that FM patients were older, with higher body mass index, with less year of study. As expected, FM showed more severe clinical symptoms and higher medication use. Data are presented in table 1. 
Table 1. Demographic and clinical characteristics for the total sample $(n=41)$.

\begin{tabular}{|c|c|c|c|c|c|}
\hline \multirow[b]{2}{*}{ Demographic variables } & \multicolumn{2}{|c|}{$\begin{array}{l}\text { Fibromyalgia } \\
\quad(\mathrm{n}=22)\end{array}$} & \multicolumn{2}{|c|}{$\begin{array}{l}\text { Controls } \\
(\mathrm{n}=19)\end{array}$} & \multirow[b]{2}{*}{ p-value } \\
\hline & Mean & SD & Mean & SD & \\
\hline Age (years) & 47.14 & 9.49 & 34.68 & 12.45 & 0.001 \\
\hline Body mass index $\$$ & 27.83 & 4.17 & 23.12 & 3.37 & 0.001 \\
\hline Years of study & 13.55 & 2.74 & 17.29 & 3.31 & $<0.001$ \\
\hline \multicolumn{6}{|l|}{ Clinical variables and psychological measures } \\
\hline Beck Depression Inventory (BDI-II) total score & 28.45 & 12.07 & 7.53 & 9.39 & $<0.001$ \\
\hline Strait-Trait Anxiety Inventory - short version (STAI-SV) - State scale & 30.00 & 7.34 & 22.32 & 6.48 & 0.001 \\
\hline Strait-Trait Anxiety Inventory - short version (STAI-SV) - Trait scale $\$$ & 27.81 & 3.44 & 18.11 & 4.53 & $<0.001$ \\
\hline \multicolumn{6}{|l|}{ Outcomes variables } \\
\hline Brazilian Pain Catastrophizing Scale (B-PCS) total score & 39.27 & 8.40 & 7.37 & 12.57 & $<0.001$ \\
\hline Brazilian Portuguese Central Sensitization Inventory (BP-SCI) & 71.18 & 13.72 & 21.37 & 11.19 & $<0.001$ \\
\hline Portuguese Profile of Chronic Pain Screen (BP-PCP:S) total score & 71.95 & 15.56 & 14.11 & 15.54 & $<0.001$ \\
\hline BP-PCP:S - Severity & 25.68 & 3.24 & 6.74 & 6.37 & $<0.001$ \\
\hline BP-PCP:S - Activity & 27.50 & 9.74 & 4.47 & 7.43 & $<0.001$ \\
\hline BP-PCP:S - Emotional burden & 18.77 & 5.00 & 2.89 & 4.01 & $<0.001$ \\
\hline Medication use & $\begin{array}{l}\text { Yes/ } \\
\text { No }\end{array}$ & $\begin{array}{c}\% \\
\text { Yes }\end{array}$ & $\begin{array}{l}\text { Yes/ } \\
\text { No }\end{array}$ & $\begin{array}{c}\% \\
\text { Yes }\end{array}$ & \\
\hline \multicolumn{6}{|l|}{ Psychiatric medication use } \\
\hline Benzodiazepine & $4 / 18$ & 18.2 & -- & -- & -- \\
\hline Antidepressant & $12 / 10$ & 54.5 & -- & -- & -- \\
\hline Anticonvulsant & $10 / 12$ & 45.5 & -- & -- & -- \\
\hline Regular analgesic use & $20 / 2$ & 90.9 & -- & -- & -- \\
\hline
\end{tabular}


Notes: $S D$ = standard deviation. All p-values are based on Mann-Whitney test, except for "regular analgesic use" which is based on Fisher's exact test. $\$=$ missing data for FM group with $n=21$.

\subsection{Cortical activation evaluated by the HbO concentration on bilateral PFC and MC evoked by thermal stimuli by right-hand immersion in water at $25^{\circ} \mathrm{C}$ and $5^{\circ} \mathrm{C}$}

\subsubsection{HbO Peak Latency evoked by thermal stimulus}

The GEE models revealed significant main effects for the group in the peak cortical activity at the thermal stimulus range from $25^{\circ} \mathrm{C}$ to $5^{\circ} \mathrm{C}$ [Wald $\chi 2=5.39, \mathrm{df}=1, \mathrm{P}=0.02$, Cramer's $\mathrm{V}=0.36]$. However, we found a difference in neither temperature effects nor interaction between temperature and group. Despite fibromyalgia showed a shorter peak latency for $\mathrm{HbO}$ at the left $\mathrm{MC}$, when compared to the within-group change, this peak latency was equal to $15.50 \%$ [mean (SD) $5.61(0.52) / 6.48(0.62)$ ] compared to $1.11 \%$ in controls $[8.09(0.90) 8.00(0.73)]$, respectively.

\subsubsection{Variations in the concentration of $\mathrm{HbO}$ on bilateral PFC and MC}

The GEE models revealed a significant temperature effect in the $\triangle \mathrm{HbO}$ at left $\mathrm{MC}$ after the thermal stimulus at $25^{\circ} \mathrm{C}$ to $5^{\circ} \mathrm{C}$ ) [Wald $\chi 2=5.71, \mathrm{df}=1, \mathrm{P}=0.02$; Cramer's $\mathrm{V}=$ 0.37]. The main effect indicated that at $5^{\circ} \mathrm{C}$ was a higher $\Delta \mathrm{HbO}$ than $25^{\circ} \mathrm{C}$. This increase in FM patients was equal to $46.15 \%$ [mean (SD) $0.39(0.06) / 0.57(0.08)$ ] compared $63.63 \%$ in controls [mean (SD) $(0.44(0.06) / 0.72(0.13)]$. However, we found a difference neither between the group nor in the interaction between temperature and group.

\subsubsection{Variations in the concentration of $\mathrm{HbO}$ evaluated by delta value upon thermal} stimulus

The GEE models revealed a significant temperature effect in the $\triangle \mathrm{HbO}$ in both $\mathrm{PFC}$ and $\mathrm{MC}$. The main effect indicated higher on the $\triangle \mathrm{HbO}$ at $5^{\circ} \mathrm{C}$ compared to $25^{\circ} \mathrm{C}$ in the $\mathrm{MC}$ 
and the PFC of both brain hemispheres. For the fibromyalgia on the left PFC this increase was equal to $32.36 \%$ [mean (SD) $0.23(0.03) / 0.34(0.05)$ ] compared to $86.66 \%$ in controls [mean (SD) $0.30(0.05) / 0.56(0.14)]$ [Wald $\chi 2=5.33, \mathrm{df}=1, \mathrm{P}=0.02$; Cramer's $\mathrm{V}=0.36$ ]. For the FM on the right PFC, this increase was equal to 54.54\% [mean (SD) $0.22(0.04) / 0.34$ (0.07)] compared to $52 \%$ in controls [mean (SD) $0.25(0.05) / 0.38(0.08)$ ] [Wald $\chi 2=5.07$, $\mathrm{df}=1, \mathrm{P}=0.02 ;$ Cramer's $\mathrm{V}=0.35]$.

For fibromyalgia on the left MC this increase was $117.64 \%$ [mean (SD) 0.17 $(0.04) / 0.37(0.06)]$ compared to $92.85 \%$ in the controls [mean (SD) $0.28(0.05) / 0.54(0.11)]$ [Wald $\chi^{2}=13.15, \mathrm{df}=1, \mathrm{P}=0.02$; Cramer's $\left.\mathrm{V}=0.57\right]$. For $\mathrm{FM}$ on the right $\mathrm{MC}$ this increase was $60 \%$ [0.15 (0.03)/0.24 (0.05) compared to $34.62 \%$ in controls [mean (SD) $0.26(0.05)$ $0.35(0.07)$ ] [Wald $\chi 2=3.82, \mathrm{df}=1, \mathrm{P}=0.02$; Cramer's $\mathrm{V}=0.30]$. We found an interaction effect between group and temperature on the activation of both MC. However, we found a difference between the groups.

insert table 2 
Table 2. Generalized Estimating Equations (GEEs) to compare the cortical activation parameters induced by thermal stimulus $\left(25^{\circ} \mathrm{C}\right.$ and $\left.5^{\circ} \mathrm{C}\right)$ on the bilateral PFC and MC between fibromyalgia patients and controls $(n=41)$. Data are presented as mean and standard error $(\mathrm{SE})(\mathrm{n}=41)$.

\begin{tabular}{|c|c|c|c|c|c|c|c|c|c|c|}
\hline & \multicolumn{2}{|c|}{ Fibromyalgia $(n=22)$} & \multicolumn{2}{|c|}{ Controls $(n=19)$} & \multirow{2}{*}{\multicolumn{2}{|c|}{ Group effect }} & \multirow{2}{*}{\multicolumn{2}{|c|}{$\begin{array}{c}\text { Temperature } \\
\text { effect }\end{array}$}} & \multirow{2}{*}{\multicolumn{2}{|c|}{$\begin{array}{c}\text { Group* } \\
\text { Temperature } \\
\text { interaction }\end{array}$}} \\
\hline & $25^{\circ} \mathrm{C}$ & $5^{\circ} \mathbf{C}$ & $25^{\circ} \mathrm{C}$ & $5^{\circ} \mathrm{C}$ & & & & & & \\
\hline & Mean (SE) & Mean (SE) & Mean (SE) & Mean (SE) & $\begin{array}{c}\text { Wald } \\
\chi^{2}\end{array}$ & $\mathbf{P}$ & $\begin{array}{c}\text { Wald } \\
\chi^{2}\end{array}$ & $\mathbf{P}$ & $\begin{array}{c}\text { Wald } \\
\chi_{2}\end{array}$ & $\mathbf{P}$ \\
\hline \multicolumn{11}{|c|}{ Oxyhemoglobin (HbO) peak latency } \\
\hline PFC left & $4.95(0.51)$ & $6.33(0.71)$ & $7.26(0.79)$ & $6.71(0.81)$ & 2.84 & 0.092 & 0.45 & 0.503 & 2.4 & 0.122 \\
\hline PFC right & $5.73(0.67)$ & $5.74(0.66)$ & $7.08(0.73)$ & $6.07(0.71)$ & 1.08 & 0.298 & 0.82 & 0.365 & 0.84 & 0.359 \\
\hline MC left & $5.61(0.52)$ & $6.48(0.62)$ & $8.09(0.90)$ & $8.00(0.73)$ & 5.39 & 0.020 & 0.63 & 0.427 & 0.95 & 0.331 \\
\hline MC right & $5.36(0.56)$ & $5.40(0.78)$ & $6.98(0.79)$ & $5.53(0.83)$ & 1.00 & 0.317 & 1.41 & 0.235 & 1.56 & 0.212 \\
\hline \multicolumn{11}{|c|}{ Delta value of oxyhemoglobin $(\triangle \mathrm{HbO})$ - from baseline to peak amplitude of the curve } \\
\hline PFC left & $0.35(0.05)$ & $0.41(0.05)$ & $0.39(0.10)$ & $0.49(0.10)$ & 0.42 & 0.519 & 2.6 & 0.107 & 0.14 & 0.712 \\
\hline PFC right & $0.35(0.07)$ & $0.44(0.06)$ & $0.32(0.05)$ & $0.44(0.06)$ & 0.05 & 0.818 & 3.17 & 0.075 & 0.08 & 0.777 \\
\hline MC left & $0.39(0.06)$ & $0.57(0.08)$ & $0.44(0.06)$ & $0.72(0.13)$ & 1.24 & 0.265 & 6.90 & 0.009 & 0.27 & 0.603 \\
\hline MC right & $0.35(0.05)$ & $0.45(0.06)$ & $0.50(0.07)$ & $0.44(0.05)$ & 1.48 & 0.223 & 0.12 & 0.729 & 2.13 & 0.144 \\
\hline \multicolumn{11}{|c|}{ Delta value of oxyhemoglobin ( $\triangle \mathrm{HbO})$ - based on the peaks of $\mathrm{HbO}$ at $5^{\circ} \mathrm{C}$ and $25^{\circ} \mathrm{C}$} \\
\hline PFC left & $0.23(0.03)$ & $0.34(0.06)$ & $0.30(0.05)$ & $0.53(0.14)$ & 2.01 & 0.157 & 5.33 & 0.021 & 0.55 & 0.457 \\
\hline PFC right & $0.22(0.04)$ & $0.34(0.07)$ & $0.25(0.05)$ & $0.38(0.08)$ & 0.3 & 0.581 & 5.07 & 0.024 & 0.02 & 0.889 \\
\hline MC left & $0.17(0.04)$ & $0.37(0.06)$ & $0.28(0.05)$ & $0.54(0.11)$ & 3.05 & 0.081 & 13.15 & $<0.001$ & 0.22 & 0.637 \\
\hline$M C$ right & $0.15(0.03)$ & $0.24(0.05)$ & $0.26(0.05)$ & $0.35(0.07)$ & 3.7 & 0.054 & 3.82 & 0.051 & $<0.01$ & 0.952 \\
\hline
\end{tabular}

Notes. $S E=$ standard error; $\triangle \mathrm{HbO}=$ Change of $\mathrm{HbO}$ from pre to post-stimulation; $\triangle H b O \_$ASE $=$Change pre to post-stimulation end; $P F C=$ pre-frontal cortex area; $M C=$ motor cortex area $; \mathrm{HO}=$ oxyhemoglobin.

\subsubsection{The fNRIS measures indexed by the delta value of oxyhemoglobin (AHbO) based on} the peaks of $\mathrm{HbO}$ at $5^{\circ} \mathrm{C}$ and $25^{\circ} \mathrm{C}$ to screen fibromyalgia and controls 
The $\Delta \mathrm{HbO}$ value based on the peaks of $\mathrm{HbO}$ at $5^{\circ} \mathrm{C}$ and $25^{\circ} \mathrm{C}$ measures in either on the right and left PFC with their respective cutoff point to reach at least $85 \%$ or higher sensitivity, $80 \%$ or higher in the specificity and the AUC analysis to discriminate fibromyalgia than controls are showed in Table 3.

-insert table 3

Table 3. ROC analysis to screening fibromyalgia cortical activation than controls according to the right and left PFC activation based on $\triangle \mathrm{HbO}$ based on the peaks of $\mathrm{HbO}$ at $5^{\circ} \mathrm{C}$ and $25^{\circ} \mathrm{C}(\mathrm{n}=42)$.

\begin{tabular}{|c|c|c|c|c|}
\hline AUC $95 \% \mathrm{CI}$ & CI $95 \%$ & Cutoffs & Sensitivity & 1 - Specificity \\
\hline \multicolumn{5}{|c|}{$\triangle H b O$ based on the peaks of $\mathrm{HbO}$ at $5^{\circ} \mathrm{C}$ and $25^{\circ} \mathrm{C}$ on the left $\mathrm{PFC}$} \\
\hline \multirow[t]{8}{*}{0.63} & $(0.45-0.80)$ & -2.0800 & 1.000 & 1.000 \\
\hline & & -.7650 & .950 & 1.000 \\
\hline & & -.4250 & .900 & 1.000 \\
\hline & & -.3950 & .900 & .938 \\
\hline & & -.3750 & .900 & .875 \\
\hline & & -.2800 & .850 & .875 \\
\hline & & -.1950 & .800 & .875 \\
\hline & & -.1750 & .800 & .813 \\
\hline \multicolumn{5}{|c|}{$\triangle \mathrm{HbO}$ based on the peaks of $\mathrm{HbO}$ at $5^{\circ} \mathrm{C}$ and $25^{\circ} \mathrm{C}$ on the right $\mathrm{PFC}$} \\
\hline \multirow[t]{6}{*}{0.60} & $(0.42-0.79)$ & -1.6000 & 1.000 & 1.000 \\
\hline & & -.5600 & .950 & 1.000 \\
\hline & & -.4750 & .950 & .938 \\
\hline & & -.3350 & .900 & .938 \\
\hline & & -.2350 & .900 & .875 \\
\hline & & -.2050 & .850 & .813 \\
\hline
\end{tabular}

AUC: area under the curve; CI: confidence interval; ROC: receiver operator characteristics. 


\subsection{Analysis of the association between the PFC and MC activation by thermal stimulus $\left(25^{\circ} \mathrm{C}\right.$ and $\left.5^{\circ} \mathrm{C}\right)$ with $\mathrm{FM}$ symptoms}

We firstly assessed if the delta value range of the $\mathrm{HbO}$ peak according to the thermal stimulus (at $5^{\circ} \mathrm{C}$ minus $\mathrm{HbO} 25^{\circ} \mathrm{C}$ ) is related to specific symptoms of FM (see Table 4). The severity of disability due to pain and the severity of central sensitization symptoms were positively correlated with the delta value of $\mathrm{HbO}$ based peak at ${ }^{\circ} \mathrm{C}$ and $25^{\circ} \mathrm{C}$ on the left PFC. Thus, the disability due to pain, central sensitization symptoms were subsequently entered as dependent variables in the multivariate linear regression model. The delta value of $\mathrm{HbO}$ based peak at $5^{\circ} \mathrm{C}$ and $25^{\circ} \mathrm{C}$ on both PFC were entered as the independent variables (Table 5).

insert table 4

Table 4. Spearman correlation coefficients of the relationship between fibromyalgia symptoms with the delta value of oxyhemoglobin $\left(\triangle \mathrm{HbO}\right.$, based on the peaks of $\mathrm{HbO}$ at $5^{\circ} \mathrm{C}$ and $\left.25^{\circ} \mathrm{C}\right)$ in either the PFC and the MC $(n=22)$.

$\begin{array}{llllllll}\text { (1) } & \text { (2) } & \text { (3) } & \text { (4) } & \text { (5) } & \text { (6) }\end{array}$

Portuguese Profile of Chronic Pain Screen (BP-PCP:S) total score (1)

1

Central Sensitization Inventory (BP-SCI) total score (2) $.64 * * \quad 1$

$(\Delta) \mathrm{HbO}$ based on the peaks of $\mathrm{HbO}$ at $5^{\circ} \mathrm{C}$ and $25^{\circ} \mathrm{C}$ on the left PCF (3) $.40 * \quad .60 * * \quad 1$

$(\Delta) \mathrm{HbO}$ based on the peaks of $\mathrm{HbO}$ at $5^{\circ} \mathrm{C}$ and $25^{\circ} \mathrm{C}$ on the right $\mathrm{PCF}$ (4) $.09 \quad .24 \quad .80 * * \quad 1$

$(\Delta) \mathrm{HbO}$ based on the peaks of $\mathrm{HbO}$ at $5^{\circ} \mathrm{C}$ and $25^{\circ} \mathrm{C}$ on the left $\mathrm{MC}(5)$ $\begin{array}{lllll}-.06 & .18 & .48 * & .69 * * & 1\end{array}$

$(\Delta) \mathrm{HbO}$ based on the peaks of $\mathrm{HbO}$ at $5^{\circ} \mathrm{C}$ and $25^{\circ} \mathrm{C}$ on the right $\mathrm{MC}$ (6)

$.01 \quad .37$

Delta value of oxy-hemoglobine (4)HbO based on peak at $5^{\circ} \mathrm{C}$ and peak at $25^{\circ} \mathrm{C}$; prefrontal cortex (PFC); motor cortex (MC). Correlation is significant at the 0.01 level (2-tailed). * Correlation is significant at the 0.05 level (2-tailed).* (BP-PCP:S).

\subsubsection{The relationship between changes in the cortical activation evoked by the thermal stimulus with symptoms of central sensitization and disability due to pain in FM}


Generalized Linear Models assessed the relationship between dependent variables (disability due to pain and central sensitization scores) and delta values of $\Delta \mathrm{HbO}$, according to the peaks $\mathrm{HbO}$ evoked by thermal stimuli of $5^{\circ} \mathrm{C}$ and $25^{\circ} \mathrm{C}$. The results of these adjusted multivariate models are presented in Table 5. On the left PCF, the $(\Delta) \mathrm{HbO}$ peak was positively correlated with the disability due to pain and the central sensitization symptoms. In contrast, on the right $\mathrm{PFC}$, the $\triangle \mathrm{HbO}$ peak was conversely associated with the disability due to pain and central sensitization symptoms.

Insert table 5

Table 5. Generalized Linear Models of the association between the disability for daily activities due to pain and central sensitization scores with the delta value of oxyhemoglobin $(\Delta \mathrm{HbO})$ - according to the peaks $\mathrm{HbO}$ evoked by thermal stimuli of $5^{\circ} \mathrm{C}$ and $25^{\circ} \mathrm{C}(\mathrm{n}=22)$.

\begin{tabular}{|c|c|c|c|c|c|c|}
\hline & B & Std. Error & CI $95 \%$ & Wald $\chi^{2}$ & Df & $\mathrm{P}$ \\
\hline \multicolumn{7}{|c|}{ Portuguese Profile of Chronic Pain Screen (BP-PCP:S) total score } \\
\hline (Intercept) & 68.693 & 2.9084 & (62.99 to 74.39$)$ & 557.871 & 1 & .000 \\
\hline $\begin{array}{l}(\Delta) \mathrm{HbO} \text { based on the peaks of } \mathrm{HbO} \text { at } 5^{\circ} \mathrm{C} \text { and } 25^{\circ} \mathrm{C} \text { on } \\
\text { the left } \mathrm{PCF}\end{array}$ & 48.866 & 15.0107 & (19.44 to 78.29$)$ & 10.598 & 1 & .001 \\
\hline $\begin{array}{l}(\Delta) \mathrm{HbO} \text { based on the peaks of } \mathrm{HbO} \text { at } 5^{\circ} \mathrm{C} \text { and } 25^{\circ} \mathrm{C} \text { on } \\
\text { the right } \mathrm{PCF}\end{array}$ & -21.847 & 10.5653 & $(-42.56$ to -1.14$)$ & 4.276 & 1 & .039 \\
\hline \multicolumn{7}{|l|}{ Central Sensitization Inventory (BP-SCI) total score } \\
\hline (Intercept) & 71.538 & 1.8309 & $(67.95$ to 75.13$)$ & 1526.683 & 1 & .000 \\
\hline $\begin{array}{l}(\Delta) \mathrm{HbO} \text { based on the peaks of } \mathrm{HbO} \text { at } 5^{\circ} \mathrm{C} \text { and } 25^{\circ} \mathrm{C} \text { on } \\
\text { the left } \mathrm{PCF}\end{array}$ & 31.991 & 9.1975 & (13.96 to 50.02) & 12.098 & 1 & .001 \\
\hline $\begin{array}{l}(\triangle) \mathrm{HbO} \text { based on the peaks of } \mathrm{HbO} \text { at } 5^{\circ} \mathrm{C} \text { and } 25^{\circ} \mathrm{C} \text { on } \\
\text { the right } \mathrm{PCF}\end{array}$ & -15.040 & 6.4418 & $(-27.67$ to -2.41$)$ & 5.451 & 1 & .020 \\
\hline
\end{tabular}

Prefrontal cortex (PFC). 


\subsubsection{The (4)HbO value based on the peaks $\mathrm{HbO}$ on PFC to mapping patients with more disability due to pain and more severe CSS}

We conducted a ROC analysis, stratifying for the cutoff point on $\triangle \mathrm{HbO}$ based on the peaks of HBO set to differentiate the fibromyalgia of controls, -0.175 on the left PFC and 0.20 in the right PFC (see table 3), respectively. The sensitivity, specificity, and AUC using these cutoff points screening patients with higher central sensitization symptoms and higher disability due to pain are presented in Table 6.

-Insert table 6

Table 6. ROC analysis to screening the severity of fibromyalgia symptoms according to the right and left PFC activation based on $\triangle \mathrm{HbO}$ based on the peaks of $\mathrm{HbO}$ at $5^{\mathrm{O}} \mathrm{C}$ and $25^{\circ} \mathrm{C}(\mathrm{n}$ $=22$ ).

\begin{tabular}{|c|c|c|c|c|}
\hline AUC 95\% CI & CI $95 \%$ & Cutoffs & Sensitivity & 1 - Specificity \\
\hline \multicolumn{5}{|c|}{ Portuguese Profile of Chronic Pain Screen (BP-PCP:S) total score } \\
\hline \multicolumn{5}{|c|}{$(\Delta) \mathrm{HbO}$ based on the peaks of $\mathrm{HbO}$ at $5^{\circ} \mathrm{C}$ and $25^{\circ} \mathrm{C}$ on the left $\mathrm{PCF}$} \\
\hline 0.58 & (CI 95\%, 0.21-0.95) & -0.175 & 100 & 100 \\
\hline \multicolumn{5}{|c|}{$(\Delta) \mathrm{HbO}$ based on the peaks of $\mathrm{HbO}$ at $5^{\circ} \mathrm{C}$ and $25^{\circ} \mathrm{C}$ on the right $\mathrm{PCF}$} \\
\hline 0.59 & (CI 95\%, 0.20-0.97) & -0.20 & 100 & 100 \\
\hline \multicolumn{5}{|c|}{ Central Sensitization Inventory (BP-SCI) total score } \\
\hline \multicolumn{5}{|c|}{$(\Delta) \mathrm{HbO}$ based on the peaks of $\mathrm{HbO}$ at $5^{\circ} \mathrm{C}$ and $25^{\circ} \mathrm{C}$ on the left PCF } \\
\hline 0.82 & $(\mathrm{CI} 95 \%, 0.61-100)$ & -0.175 & 100 & 100 \\
\hline \multicolumn{5}{|c|}{$(\Delta) \mathrm{HbO}$ based on the peaks of $\mathrm{HbO}$ at $5^{\circ} \mathrm{C}$ and $25^{\circ} \mathrm{C}$ on the right $\mathrm{PCF}$} \\
\hline 0.68 & (CI 95\%, 0.29-100) & -0.20 & 100 & 100 \\
\hline
\end{tabular}

AUC: area under the curve; CI: confidence interval; ROC: receiver operator characteristics. 


\section{DISCUSSION}

These results showed that the experimental paradigm of contrasting thermal stimuli, from $25^{\circ} \mathrm{C}$ to $5{ }^{\circ} \mathrm{C}$, based on $\mathrm{HbO}$ might be a useful surrogate marker to identify dysfunction in pain processing areas. We found a larger temperature effect in the $\Delta \mathrm{HbO}$ in the $\mathrm{MC}$ of fibromyalgia than controls. In contrast, on the left PFC, this increase in the $\Delta \mathrm{HbO}$ was lower in fibromyalgia than in controls. These results corroborate the hypothesis that the magnitude of changes in the cortical activation based on the $\Delta \mathrm{HbO}$ (peaks of $\mathrm{HbO}$ from $5{ }^{\circ} \mathrm{C}$ to $25^{\circ} \mathrm{C}$ ) at the PFC might be a sensitive marker to map the dysfunctional neuronal activities. They permit to differentiate the activation pattern in fibromyalgia compared to controls and to identify those fibromyalgia patients prone to disability due to pain and more severe CSS.

The hemodynamic signal is known to have inter-subject variability and inter-trial variations. Despite this, these results showed that these indirect metabolic activity measures might help identify dysfunctional cortical processes associated with the severity of clinical symptoms in a well-defined experimental paradigm. We found that fibromyalgia subjects showed a shorter peak latency of the $\mathrm{HbO}$ at the left MC compared to controls. This result is aligned with a previous study that found lower maximal and average changes in $\mathrm{HbO}$ concentration at both the left and the right PFC compared to healthy controls during a breathholding task. ${ }^{(24)}$ Also, another study using fNIRS found reduced brain activity over the frontal regions during a verbal fluency test (VFT) in fibromyalgia compared to controls. ${ }^{(25)}$ According to earlier studies, a more significant short intracortical inhibition was found in fibromyalgia compared to healthy subjects. ${ }^{(26)}$ Thus, this set of findings suggests reduced cortical activation in fibromyalgia, which may indicate deterioration in cortical processing function.

The relevance of these findings is to show a framework for understanding the relationship between cortical areas' function in pain processing and clinical symptoms related 
to CSS and disability due to pain. In this regard, they open an avenue to identify measures with the potential to be biomarkers, since they integrate the function of cortical areas involved in underpinning fibromyalgia symptoms. These areas have also been targeted by therapeutic approaches, such as tDCS and repetitive TMS (rTMS). According to experimental studies, there is an analgesic effect on pain induced by non-invasive brain stimulation techniques such as rTMS ${ }^{(27)}$ and tDCS. ${ }^{(28,29,30,31,32)}$ The extended home-based use of tDCS on the left dorsolateral PFC (DLPFC) improved pain, psychological symptoms, sleep quality, and disability due to fibromyalgia. ${ }^{(28)}$ The use of tDCS on the left DLPFC improved attention, working memory, and pain in fibromyalgia ${ }^{(3334)}$ and depressive symptoms in major depressive disorders. ${ }^{(35,36)}$ In contrast, activation of the M1 seems to interact with the cortical regions responsible for pain processing and modulation function on the M1-thalamic inhibitory networks.

Accordingly, these findings have the potential to reveal whether treatment effects are related to changes in these cortical processing areas. Their relevance from a clinical perspective is to generate data that integrate measures of a pathological state that drives PFC changes, culminating in pain amplification and cognitive problems. This hypothesis is supported by preclinical studies on chronic neuropathic pain, where a loss in activity of prelimbic PFC pyramidal neurons was observed, which signaled to the PAG, a central structure of the descending modulation pain system. ${ }^{(37,38)}$ Hence, PFC deactivation might explain the disruption of this descending analgesic circuitry and susceptibility to greater clinical symptoms. Human neuroimaging studies also show a loss of fiber track density and reorganization of white matter connectivity from the PFC to the insula, basal ganglia, and other regions involved in pain processing. ${ }^{(39,40)}$ These changes also encompass the anterior cingulate cortex (ACC), and they indicate a disruption of the PFC output in chronic pain patients. ${ }^{(39,40)}$ 
The involvement of PFC in pain processing is supported by a human experimental study using a standardized stimulus. Unilateral right accessory spinal nerve electrical stimulation showed an ipsilateral DLPFC activation. ${ }^{(41)}$ Despite the sample of this experimental study comprising only healthy males, it corroborates the role of the PFC by functional spectroscopic mapping of pain-processing cortical areas related to sensorydiscriminative and affective-motivational pain dimensions. Likewise, results of a metaanalysis of studies employing experimental pain stimuli indicate a positive association of the following brain areas with pain processing: primary and secondary somatosensory cortices, insular cortex, ACC, PFC, and thalamus. ${ }^{(42)}$ Thus, this result find support in the anatomic perspective, since the discrimination of pain intensity by the ventral pathway activates the PFC bilaterally, and the spatial discrimination by the dorsal direct path from the posterior parietal cortex triggers the DLPFC. ${ }^{(43)}$

The main contribution of our findings is to extend the literature integrating neurophysiological measures with clinical data with the perspective of accelerating the translation of surrogate measures to results to apply at the bedside. The $\Delta \mathrm{HbO}$ based on the peaks at $5{ }^{\circ} \mathrm{C}$ and $25{ }^{\circ} \mathrm{C}$ at the left PFC was positively correlated with the disability due to pain and CSS. In contrast, the change in the $\triangle \mathrm{HbO}$ at the right PFC by the same thermal stimulus was conversely correlated with the severity of these clinical symptoms. This suggests an imbalance of inter-hemispheric activation. It tends to be more pronounced in the left, either in the MC and PFC. One hypothesis to explain these findings is that some target areas are activated to the detriment of other circuits' deactivation. Thus, this imbalance may be related to functional lateralization of the amygdala in the context of pain. In general, the amygdala's right central nucleus tends to have a pronociceptive role, while the left has an antinociceptive role. ${ }^{(44)}$ One hypothesis is that the disturbed balance of this system results in chronic pain conditions. Although the explanation for this imbalance is not clear, it may be 
due to the maintenance of neuronal hyperexcitability in the central left nucleus of the amygdala to counteract the pain-driving effect of the right central nucleus of the amygdala. (44) However, studies related to amygdala lateralization in the context of pain are only beginning, and there are many different elements to consider that will vary significantly based on pain mechanism. We acknowledge that this hypothesis remains relatively broad, but a better comprehension of lateralization on pain processing is relevant to the therapeutic perspective mentioned above. However, the specific intricacies necessary to fully understand how lateralization functions on pain will need further studies that specifically address side as a variable.

The receiver operator characteristics (ROC) analysis was used to screen the severity of fibromyalgia symptoms observed after the left PFC activation based on $\Delta \mathrm{HbO}$ peaks at 25 ${ }^{\circ} \mathrm{C}$ and $5{ }^{\circ} \mathrm{C}$. The cutoff was defined setting the AUC to offers $100 \%$ sensitivity and $98 \%$ specificity to screen fibromyalgia patients versus controls (Table 2). It offered an AUC of 0.82 to screen for severity of CSS. As mentioned above, this result can be a consequence of lateralization of the antinociceptive response. This more considerable change of cortical activation in fibromyalgia suggests a deteriorated function of the PFC in pain processing. More precisely, from a conceptual perspective, our findings might explain the pathophysiological processes that underlie fibromyalgia, since they integrate the severity of symptoms with dysfunctional changes in cortical areas involved in the cardinal sign of PFC dysfunction, such as cognitive impairment. ${ }^{(45)}$ Additionally, the dysfunction of the PFC might explain the central sensitization-related clinical variables, such as depressive symptoms, insomnia symptoms, perceived level of disability, ${ }^{(46}$ duration of pain, current pain intensity, ${ }^{(47)}$ average pain intensity, and pain catastrophizing. ${ }^{(33)}$

We assumed that cortical activation changes could not be interpreted as a direct response to nociceptive stimuli since the hemodynamic response is an alternative marker of 
neuronal activity. Accordingly, the increase in cortical activation in the PFC during the thermal tests and its association with clinical symptoms due to pain reinforce the hypothesis that, at some level, that these changes are related to cortical pain processing and correlate symptoms. Even though we cannot interpret them as a cause-effect response, their contextualized interpretation can help investigate the function of cortical brain in targeting areas involved in pain processing and areas targeted by therapeutic approaches. Our findings agree with some of the literature supporting fNIRS measures as a reliably sensitive central measure to comprehend the cortical effect of painful stimulation. ${ }^{(48)}$ Yücel et al. (2015) found that in the healthy subject, the BOLD signals assessed by fNIRS detected a greater activation in the M1 upon painful stimulus but no critical changes in the PFC. Although many studies have investigated cortical activation using fNIRS in fibromyalgia, a novelty of the current study is the distinct paradigm used. ${ }^{(48,49)}$ We used two specific thermal stimuli, one painful $\left(5{ }^{\circ} \mathrm{C}\right)$ and another non-painful $\left(25^{\circ} \mathrm{C}\right)$, to evaluate whether they evoked a contrastable effect on cortical activation, and these changes could be related to clinical symptoms. We realize that it is a positive contribution to makes comparisons more feasible. Although these results indicate changes by indirect means (metabolic and vascular), they give us new insights to study in real time the effect of different paradigms to evaluate cortical dysfunction related to chronic pain. Additionally, they may be an entry port to assess the complex pain-related neural network and to understand the role of the MC and PFC in processing pain signals.

Although these results offer a perspective to comprehend the role of target areas related to pain and emotion using fNIRS that permits an assessment in real time, we need parsimony in their interpretation owing to some limitations in the methods and study design. First, it is a challenge to maintain fibromyalgia patients in the same position for any length of time, and they may even experience scalp pain during hair manipulation. For these reasons, we removed some channels in some cases, and sometimes the quality of the signal was poor. 
However, we know these difficulties are intrinsic to this type of measure. Second, we identify differences between groups related to age, formal education years, psychiatric disorders, and medication, several of which are expected. Even though some confounding effects cannot be fully controlled, we found results that indicate differences between groups with biological plausibility. Third, this is a physiological-basis study involving cortical pain processing and given the known difference between sexes in pain processing, we included only female subjects. We understand that this restricts external validity. However, it permitted us to reduce the potential confounding effect of sex on our measures. This is plausible since women are more susceptible to negative emotional responses such as fear of pain, ${ }^{(50)}$ stress, and anxiety. ${ }^{(51)}$ Finally, further research is needed to assess the cortical brain activation in chronic pain under different experimental paradigms, such as behavioral tests to determine a cognitive and emotional response, motor tasks, and changes related to effects of different therapeutic approaches (e.g., tDCS, TMS, etc.).

In conclusion, these results indicate that cortical activation based on the $\Delta \mathrm{HbO}$ on the PFC might be a sensitive marker to discriminate fibromyalgia's cortical processing and to screen those patients with more disability due to pain and more severe CSS. Overall, they offer insight toward comprehending the cortical function in the pathophysiology of primary chronic pain as well as the modifications of the cortical function of these target areas in response to an effective treatment.

\section{Contributorship}

$D G D, M Z, I L S T, F F, W C$ were involved in the study concept and design, acquisition of data or analysis, and interpretation of the data. $D G D$ and $M Z$ were involved in data acquiring, analysis or interpretation. $D G D, M Z$, and $W C$ contributed to drafting/revising the manuscript for 
relevant intellectual content. All authors contributed to the approval of the final version to be published.

\section{DISCLOSURES}

Research funding for Brazilian agencies: i) Committee for the Development of Higher Education Personnel—CAPES (MZ, post-doctorate scholarship). (ii) National Council for Scientific and Technological Development - CNPq (grant nos. 302688/2017-0 and 420826/2018-1 to W. C.). (iii) Postgraduate Research Group at the Hospital de Clínicas de Porto Alegre (grant no. 20170330). Brazilian Innovation Agency (FINEP [Financiadora de Estudos e Projetos]) (process number 1245/13. Fundação de Amparo à Pesquisa do Estado do Rio Grande do Sul (FAPERGS)- grant no WC, 17/2551-0001 087-6 and 17/2551-0001 476-6).

W. C. agrees to be accountable for all aspects of the work, ensuring that questions related to the accuracy or integrity of any part of the work are appropriately investigated and resolved.

\section{Declaration of conflict of interests}

The authors declare that there are no financial or other relationships that might lead to conflict of interests.

\section{REFERENCES}


1. Wolfe F, et al. 2016 Revisions to the 2010/2011 fibromyalgia diagnostic criteria. Seminars in Arthritis and Rheumatism. 46, 319-329; 2016.

2. Caumo W et al. "The Central Sensitization Inventory Validated and Adapted for a Brazilian Population: Psychometric Properties and Its Relationship with Brain-Derived Neurotrophic Factor.” Journal of Pain Research, 10, 2109-2122 (2017).

3. Mills, EP. "Brainstem Pain-Control Circuitry Connectivity in Chronic Neuropathic Pain." Journal of Neuroscience 2018, 38 465-73 (2018).

4. Napadow V et al. "Intrinsic Brain Connectivity in Fibromyalgia Is Associated with Chronic Pain Intensity." Arthritis \& Rheumatism 62, 2545-2555 (2010).

5. Peng, K et al. "Morphine Attenuates FNIRS Signal Associated With Painful Stimuli in the Medial Frontopolar Cortex (Medial BA 10)." Frontiers in Human Neuroscience 12, 394. https://doi.org/10.3389/fnhum.2018.00394 (2018).

6. Nurcan Ü, Zeller J, Kewenig S, Kittel-Schneider S, Fallgatter AJ, and Claudia Sommer. "Increased Cortical Activation upon Painful Stimulation in Fibromyalgia Syndrome." BMC Neurology 15, 210 DOI 10.1186/s12883-015-0472-4 (2015).

7. Debbie LM , Javin S Sandhu, and Jones AK. "Brain Imaging of Pain: State of the Art." Journal of Pain Research 9, 613-24 (2016).

8. Wei-Yi O, Stohler CS , Herr DR. "Role of the Prefrontal Cortex in Pain Processing." Molecular Neurobiology 56, 1137-66 (2019).

9. Lefaucheur J-P, et al. "Evidence-Based Guidelines on the Therapeutic Use of Transcranial Direct Current Stimulation (TDCS)." Clinical Neurophysiology 128: 56-92, (2017).

10. Yu ZCB., Zhang W., Chen W., Qi Q, and MiaoY. 2017. "Effiectiveness and Safety of Transcranial Direct Current Stimulation in Fibromyalgia: A Systematic Review and Meta-Analysis.” Journal of Rehabilitation Medicine 49, 2-9 (2017). 
11. Wen-Hsuan H., Wang T-Y., and Kang J-H. 2016. "The Effects of Add-on Non-Invasive Brain Stimulation in Fibromyalgia: A Meta-Analysis and Meta-Regression of Randomized Controlled Trials. Rheumatology 55,1507-17 (2016).

12. Firbank, M, Elwell CE, Cooper CE, and Delpy DT. 1998. "Experimental and Theoretical Comparison of NIR Spectroscopy Measurements of Cerebral Hemoglobin Changes.” Journal of Applied Physiology 85: 1915-21 (1985).

13. Kurth C D., Hanli Liu H., Thayer WS, and B. Chance. 1995. “A Dynamic Phantom Brain Model for Near-Infrared Spectroscopy.” Physics in Medicine and Biology 40, 2079-92 (1995).

14. Wolfe, Frederick, Niklaus Egloff, and Winfried Häuser. 2016. "Widespread Pain and Low Widespread Pain Index Scores among Fibromyalgia-Positive Cases Assessed with the 2010/2011 Fibromyalgia Criteria." Journal of Rheumatology 43: 1743-48 (2016).

15. Barati Z, Zakeri I, Pourrezaei K., "Functional near-infrared spectroscopy study on tonic pain activation by cold pressor test." Neurophoton 4, 015004 , doi: 10.1117/1.NPh.4.1.015004 (2017).

16. Plichta MM., et al 2006. "Event-Related Functional near-Infrared Spectroscopy (FNIRS): Are the Measurements Reliable?" NeuroImage 31,116-24 (2006).

17. Caumo W., et al. "Cross-Cultural Adaptation and Validation of the Profile of Chronic Pain: Screen for a Brazilian Population.” Pain Medicine (United States) 14, 52-61 (2013).

18. Caumo W., et al. The Central Sensitization Inventory validated and adapted for a Brazilian population: psychometric properties and its relationship with brain-derived neurotrophic factor. J Pain Res. 10, 2109-2122 (2017).

19. Gorenstein, C., and Andrade L. "Validation of a Portuguese Version of the Beck Depression Inventory and the State-Trait Anxiety Inventory in Brazilian Subjects.” 
Brazilian Journal of Medical and Biological Research 29, 453-57, (1996).

20. Kaipper MB, Chachamovich E, HidalgoMP., Torres ILS., and Caumo W. 2010. "Evaluation of the Structure of Brazilian State-Trait Anxiety Inventory Using a Rasch Psychometric Approach. Journal of Psychosomatic Research, 68, 223-233 (2009).

21. Sehn F., et al. Cross-cultural adaptation and validation of the Brazilian Portuguese version of the pain catastrophizing scale. Pain Med. 13,1425-35 (2012).

22. Ialongo C. 2016. "Understanding the Effect Size and Its Measures Lessons in Biostatistics.” Biochemia Medica, 26,150-163 (2016).

23. "Free A-Priori Sample Size Calculator for Hierarchical Multiple Regression - Free Statistics Calculators.” n.d. Accessed January 19, 2021. https://www.danielsoper.com/statcalc/calculator.aspx?id=16.

24. Chen W-T., Chuan-Hsiang Y., and Chia-Wei Sun. "Altered Near-Infrared Spectroscopy Response to Breath-Holding in Patients with Fibromyalgia.” Journal of Biophotonics 12, e201800142. https://doi.org/10.1002/jbio.201800142 (2019).

25. Han CP., Tang KT., Chen YH., Sun CW., Huang CM., and Chen DH. "Reduced Frontal Activity during a Verbal Fluency Test in Fibromyalgia: A near-Infrared Spectroscopy Study." Journal of Clinical Neuroscience 50, 35-40 (2018).

26. Cardinal TM., et al. "Differential Neuroplastic Changes in Fibromyalgia and Depression Indexed by Up-Regulation of Motor Cortex Inhibition and Disinhibition of the Descending Pain System: An Exploratory Study.” Front Hum Neurosci 25, 138. doi: 10.3389/fnhum.2019.00138. eCollection (2019).

27. Knijnik, LM., et al. "Repetitive Transcranial Magnetic Stimulation for Fibromyalgia: Systematic Review and Meta-Analysis.” Pain Practice 16, 294-304 (2015).

28. Brietzke, Aline P., et al.“Large Treatment Effect With Extended Home-Based Transcranial Direct Current Stimulation Over Dorsolateral Prefrontal Cortex in 
Fibromyalgia: A Proof of Concept Sham-Randomized Clinical Study." Journal of Pain 21, 212-24 (2020).

29. O'Connell NE, Wand BM, Marston L, Spencer S, DeSouza LH. Non-invasive brain stimulation techniques for chronic pain. Cochrane Database of Systematic Reviews. Issue 4. Art. No.: CD008208. DOI: 10.1002/14651858.CD008208.pub3, (2014).

30. Asbjørn JF., Hansen AO., and Aslaksen PM. 2015. "Transcranial Direct Current Stimulation as a Treatment for Patients with Fibromyalgia: A Randomized Controlled Trial. Pain 156, 62-71. (2015)

31. Fregni F., el al. “A Randomized, Sham-Controlled, Proof of Principle Study of Transcranial Direct Current Stimulation for the Treatment of Pain in Fibromyalgia." Arthritis and Rheumatism. 54, 3988-3998 (2006).

32. Valle A., et al. "Efficacy of Anodal Transcranial Direct Current Stimulation (TDCS) for the Treatment of Fibromyalgia: Results of a Randomized, Sham-Controlled Longitudinal Clinical Trial.” Journal of Pain Management, 2, 353-361 (2009).

33. Silva AF., et al. "Anodal Transcranial Direct Current Stimulation over the Left Dorsolateral Prefrontal Cortex Modulates Attention and Pain in Fibromyalgia: Randomized Clinical Trial.” Scientific Reports. https://doi.org/10.1038/s41598-017$\underline{00185-\mathrm{w}}(2017)$.

34. Santos VSS., et al. "Cognitive Effects of Transcranial Direct Current Stimulation Combined with Working Memory Training in Fibromyalgia: A Randomized Clinical Trial.” Scientific Reports. https://doi.org/10.1038/s41598-018-30127-z (2018).

35. Brunoni AR., et al. "Trial of Electrical Direct-Current Therapy versus Escitalopram for Depression." New England Journal of Medicine. https://doi.org/10.1056/nejmoa1612999, (2017).

36. Fregni F, et al. "Evidence-Based Guidelines and Secondary Meta-Analysis for the Use of 
Transcranial Direct Current Stimulation (TDCS) in Neurological and Psychiatric

Disorders Int J Neuropsychopharmacol 26, pyaa051. doi: 10.1093/ijnp/pyaa051. Online ahead of print (2020).

37. Junting H., et al.. “A Neuronal Circuit for Activating Descending Modulation of Neuropathic Pain.” Nature Neuroscience 22, 1659-68 (2019).

38. John C., Sheets PL. 2018. “Altered Excitability and Local Connectivity of MPFC-PAG Neurons in a Mouse Model of Neuropathic Pain.” Journal of Neuroscience 38, 829-39 (2019).

39. Geha PY., Baliki MN., Harde NR., Bauer WR., Parrish TB., Apkarian AV. "The Brain in Chronic CRPS Pain: Abnormal Gray-White Matter Interactions in Emotional and Autonomic Regions.” Neuron 60, 570-81 (2008).

40. Davis W., et al. 2015. "Unique Microstructural Changes in the Brain Associated with Urological Chronic Pelvic Pain Syndrome (UCPPS) Revealed by Diffusion Tensor MRI, Super-Resolution Track Density Imaging, and Statistical Parameter Mapping: A MAPP Network Neuroimaging Study.” PLoS ONE 10, 1-30 (2015).

41. Bandeira, Janete Shatkoski, Luciana da Conceição Antunes, Matheus Dorigatti Soldatelli, João Ricardo Sato, Felipe Fregni, and Wolnei Caumo. 2019. "Functional Spectroscopy Mapping of Pain Processing Cortical Areas during Non-Painful Peripheral Electrical Stimulation of the Accessory Spinal Nerve.” Front. Hum. Neurosci., 13, https://doi.org/10.3389/fnhum.2019.00200 (2019).

42. Apkarian AV., Bushnell MC., Treede RD., Zubieta JK. 2005. "Human Brain Mechanisms of Pain Perception and Regulation in Health and Disease.” Eur J Pain 9, 463-84 (2005).

43. Ong W-Y., Stohler CS., Herr DR. Role of the Prefrontal Cortex in Pain Processing. Mol Neurobiol. 56, 1137-1166 (2019). 


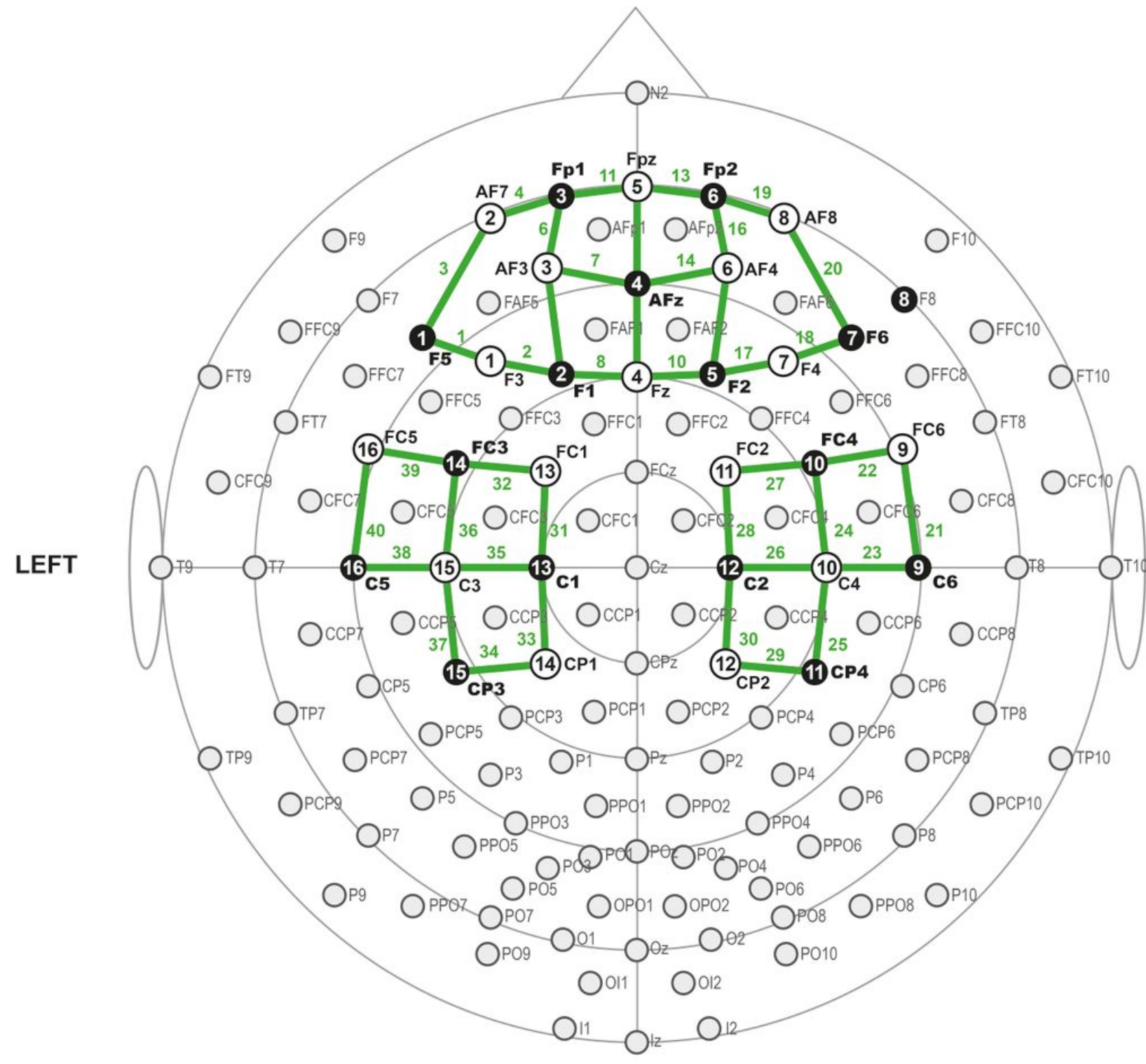

RIGHT

Figure 1

The fNIRS' optodes montage. Black dots represent detectors, and white dots represent sources. LEFT PREFRONTAL CORTEX = Channel 1-9 plus 11 and 12. RIGHT PREFRONTAL CORTEX- Channel $12-20$ plus Channel 9 and 10. RIGHT MOTOR CORTEX - Channel 21-30. LEFT MOTOR CORTEX - Channel 3140. 


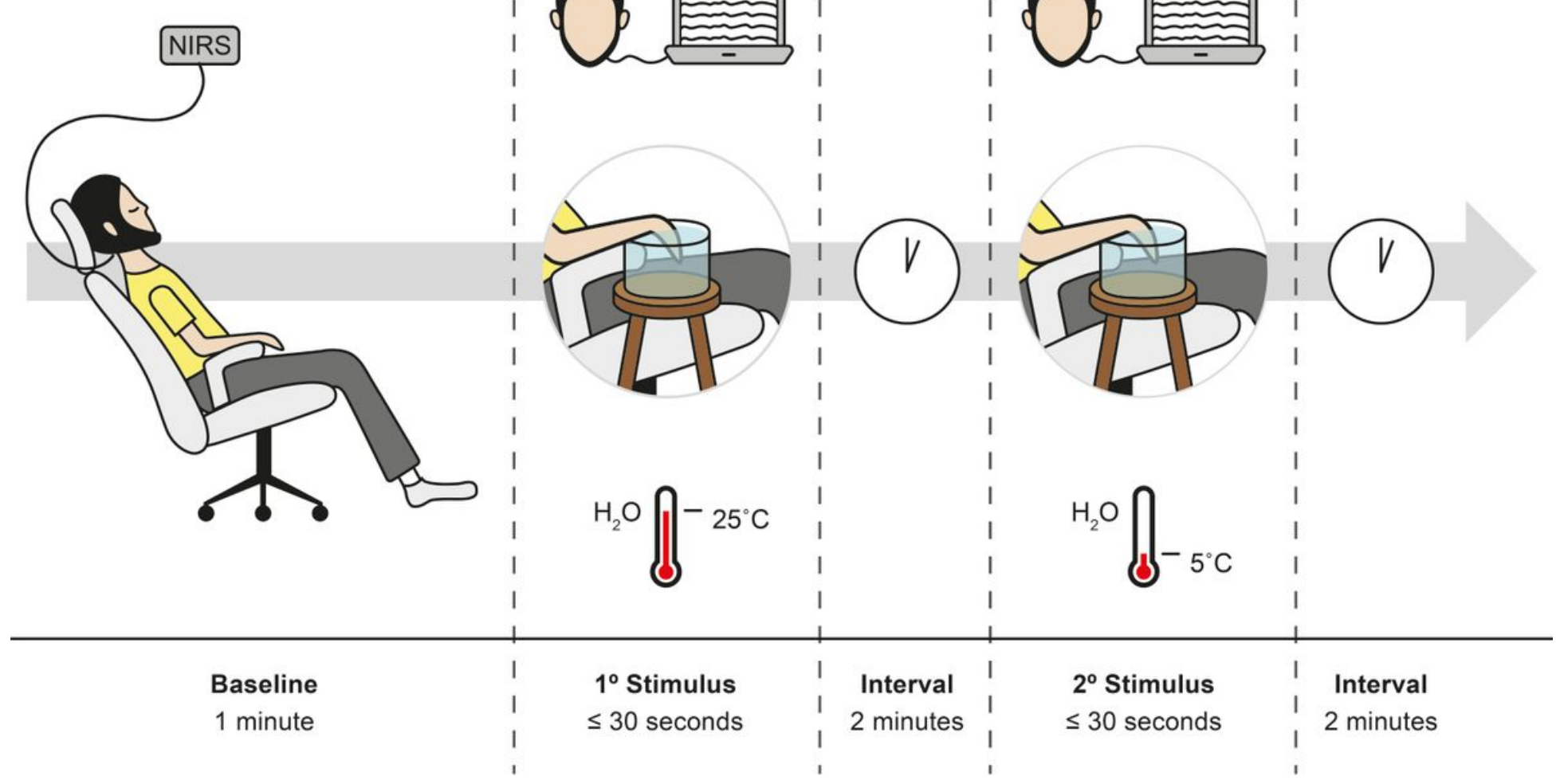

Figure 2

Timeline of the experimental paradigm. Timeline of each assessment pre- and post-thermal stimuli with the temperature at $25^{\circ} \mathrm{C}$ and $5^{\circ} \mathrm{C}$. The cold test was induced by the immersion of the right hand in the water for 30 seconds or until feeling the first pain sensation, with the temperature of $25^{\circ} \mathrm{C}$ and $5^{\circ} \mathrm{C}$ and a break of 2 minutes between each trial. The temperature was controlled through a digital thermometer.

\section{Supplementary Files}

This is a list of supplementary files associated with this preprint. Click to download.

- Appendix.docx 